\title{
Effects of Developmental Abuse and Symptom Suppression among Traumatized Veterans
}

\author{
John J. Whelan \\ Private Practice, Halifax, Nova Scotia, Canada \\ Email: j.whelanphd@gmail.com
}

Received 17 February 2015; accepted 3 April 2015; published 8 April 2015

Copyright (C) 2015 by author and Scientific Research Publishing Inc.

This work is licensed under the Creative Commons Attribution International License (CC BY). http://creativecommons.org/licenses/by/4.0/

(c) (i) Open Access

\begin{abstract}
While much of the research on military posttraumatic stress disorder (PTSD) focuses on warzone reactions, a burgeoning literature highlights complex relationships between childhood adversity and adult-onset PTSD. However, conceptual efforts to delineate the effects of childhood abuse on treatment trajectories for traumatized military veterans are lacking. This study compared trauma and psychological symptom profiles for developmentally abused and non-abused Canadian Forces (CF) veterans $(\mathrm{N}=108)$ diagnosed with operational PTSD. Subscale scores from the Detailed Assessment of PTSD Scale (DAPS) and the Personality Assessment Inventory (PAI) were submitted to MANOVA. The analysis resulted in a composite variable reflecting' symptom suppression efforts' that separated abused veterans $(n=55)$ from non-abused veterans $(n=53)$. Post hoc analyses showed significant differences between the abused sub-groups (i.e., physical and sexual abuse [n = 15]; physical abuse only [ $n=17]$; sexual abuse only [ $n=23]$ ) and the non-abused group. Veterans with abuse histories had higher symptom suppression scores, reflecting higher levels of substance abuse, post-traumatic dissociation, interpersonal mistrust, as well as, lower depression and PTSD impairment scores. Implications for clinicians and an alternative intervention for treating traumatized military personnel with histories of developmental abuse are discussed.
\end{abstract}

\section{Keywords}

Military PTSD, Childhood Abuse, Trauma Treatment, Group Therapy, Complex Trauma

\section{Introduction}

Numerous studies have linked military PTSD onset and symptom severity with combat experiences. Conse- 
quently, treatment efforts typically focus on aspects of military deployments, despite evidence that up to 90 percent of military veterans report exposure to non-military trauma, including high rates of developmental abuse (Cabrera, Hoge, Bliese, Castro, \& Messer, 2007; Felitti \& Anda, 2010; Forbes et al., 2013; Kozaric-Kovacic, 2008; Schumacher, Coffey, \& Stasiewicz, 2006). In military studies, childhood physical and sexual abuse, living with a mentally ill caregiver, and witnessing domestic violence have been associated with post-deployment depression and PTSD (Cabrera et al., 2007; Van Voorhees et al., 2012). Prospective studies have reported direct links between developmental abuse and neglect, and subsequent military PTSD, independent of combat exposure (Mikulak, 2012; Solomon, Zur-Noah, Horesh, Zerach, \& Keinan, 2008). Childhood trauma has also been linked with increased severity of military PTSD symptoms (Seifert, Polusny, \& Murdoch, 2011); these incremental effects appear to be more pronounced in cases of low combat exposure (Owens et al., 2009). While this research indicates direct relationships between adverse childhood events and subsequent military PTSD, much less is known about PTSD symptom presentation and treatment response among military personnel with histories of developmental adversity.

The prevalent evidence-based interventions for combat-related trauma are individually-focussed, cognitive processing therapy (CPT) and prolonged exposure (PE) therapy, in particular, (Forbes et al., 2013; Kitchiner, Roberts, Wilcox, \& Bisson, 2012; Rademaker et al., 2009; Sharpless \& Barber, 2011) which do not usually focus on non-military trauma or comorbid issues (Brown et al., 1999; Forbes et al., 2013; Ravindran \& Stein, 2009; Schottenbauer, Glass, Arnkoff, \& Gray, 2008; Rademaker et al., 2009). Despite the efficacy of these interventions, symptom persistence has been reported at rates of up to 50\%, especially in of cases of diagnostic comorbidity (Baker, Neivergelt, \& Risbrough, 2009; Nilamadhab, 2011; Norman, Tate, Anderson, \& Brown, 2007; Wampold et al., 2010). In the landmark study of the long-term consequences of adverse childhood events (ACE), Felitti and Anda (2010) argued that in order to fully understand adult psychopathology we must move beyond the presenting symptom of the moment and attempt to understand patient issues within the full context of their lives. In sum, it seems clear from these studies that we need to better understand possible long-term effects of developmental abuse among traumatized military personnel who present for treatment.

Purpose of study. Military veterans, many of whom are treated for PTSD (e.g., PE, CPT, and pharmacotherapy) before medical release, frequently experience significant difficulties transitioning to civilian life (Thompson et al., 2011). While the exact reasons for post-military declines are unclear, given that military PTSD interventions usually focus on operational experiences, it is possible that PTSD relapse and social isolation following medical release are related to untreated developmental abuse (Whelan, 2013a). To explore this possibility, comparisons of trauma and psychological symptom profiles were conducted for abused and non-abused veterans through the lens of childhood physical and sexual abuse. It was hypothesized that traumatized veterans who report childhood sexual and physical abuse would exhibit more severe trauma and psychological symptom profiles compared to traumatized veterans without abuse histories.

\section{Method}

Procedure. Chart reviews were conducted for 108 veterans referred for assessment and treatment at a private clinic in Atlantic Canada during 2008-2012. All clients were assessed during intake by a staff psychologist and reviewed by the senior psychologist. PTSD diagnoses were based on the results of clinical interviews and equivalent findings from the Clinician Administered PTSD Scale (CAPS) (Blake et al., 2000), the Detailed Assessment of PTSD Scale (DAPS) and the Personality Assessment Inventory (PAI). Given the normative data, validity scales, and attention to associated features provided by the DAPS and the PAI, only results from these measures were included in the study.

Inclusion/Exclusion criteria. Participant charts were included for review if: a) the assessment diagnosis met the criteria for operationally-related PTSD; and b) if the resulting profiles for completed DAPs and the PAI were psychometrically valid. Participant charts for Royal Canadian Mounted Police (RCMP) veterans were not included in this study.

Ethical considerations. The research proposal was reviewed with Veterans Affairs Canada and with the provincial regulatory body for psychologists. Given that client confidentiality was assured, no risks to participants were identified, and with the potential of contributing to the understanding of military PTSD, permission was granted by both organizations to proceed with the study. 


\section{Measures}

Clinical Interviews. Participants were asked about their life situations before, during, and after leaving the military, including developmental, family, and military experiences, and history of substance use. Other information included age, marital and family status, military rank, service element, and deployment history. Participants were separated into two main groups based on their responses (yes/no) to the life events portion of the DAPS (described below): 1) Physical assault by an adult resulting in injuries before the age of 16; and 2) unwanted or forced sexual contact before the age of 16 .

Personality Assessment Inventory. The PAI (Morey, 1991) is a multi-scale test of psychological functioning comprised of 22 non-overlapping scales (e.g., depression, anxiety, aggression) in adults; the 2008 update (Morey, 2008) includes interpretive scoring software. The PAI contains validity scales (to measure possible faking, exaggeration or defensiveness), clinical scales, treatment risk factors (e.g., suicidal ideation), and interpersonal functioning. Respondents are asked to rate their responses on a 4-point scale.The scale is written at a grade 4 level and takes approximately 45 minutes to complete. The test manual provides extensive psychometric data; Cronbach's alpha ratings for the clinical and treatment scale ranges are .82 to .93. Test-retest reliability over a two-week period ranged between .67 to .90 . The test manual outlines good discriminant and convergent studies with a number of other psychological measures.

Detailed Assessment of Posttraumatic Stress. The DAPS (Briere, 2001) is a 105-item inventory providing detailed information on various Criterion A events (e.g., natural disasters, war, rape, physical assault, child abuse), psychological reactions (cognitive, emotional, and dissociative), posttraumatic stress symptoms (re-experiencing, avoidance, hyperarousal), and level of posttraumatic impairment. Respondents are asked to rate their answers on a 5-point scale. It is appropriate for clients aged 18 to 91 years and takes 20 - 30 minutes to complete. Two validity scales evaluate positive and negative bias, and three supplementary scales evaluate event-related dissociation, substance abuse, and suicidality. Standardization studies of the DAPS involved a normative group of adults reporting at least one DSM-IV-type trauma and clinical and nonclinical validity subjects. Cronbach’s alpha ratings for the clinical scales were estimated at .88 to .92 (Cronbach's alpha). Diagnoses of PTSD have good sensitivity (.88) and specificity (.86) when compared to the clinician administered PTSD scale (CAPS).

\section{Results}

Description of Participants. Charts were reviewed for 108 military veterans being assessed at a private clinic in Atlantic Canada. Participants were separated into two groups: developmental abuse ( $=55$ ); 86\% male; $14 \%$ female; average age: 47 years; service element: 44\% Army; 37\% Navy; 14\% Air Force; 5\% combined service); and no abuse ( $\mathrm{n}=53$ ); 91\% male; 9\% female; average age: 47 years; service element: 47\% Army; 49\% Navy; 2\% Air Force; $2 \%$ combined service). T-tests of between-group differences for the demographic variables were nonsignificant at $\alpha=.01$ (Pagano, 1997).

Analysis Design. The main research question was whether the trauma and mental health measures differentiated traumatized veterans with developmental abuse histories from veterans who did not experience developmental abuse. The data were analyzed using SPSS, Version 20 (IBM Corp., 2011). Prior to conducting a oneway multivariate analysis of variance (MANOVA), a series of Pearson correlations was performed for all nonredundant subscales of the PAI and DAPS to test the MANOVA assumption that the dependent variables were moderately correlated (Tabachnick \& Fidell, 2006). As shown in Table 1, the pattern of inter-correlations supported the use of MANOVA procedure for eleven variables. The Box's M value of 89.59 was associated with a $p$-value of .119 and nonsignificant. This was interpreted as supporting equality of the covariance matrices across the groups. A random inspection of bivariate scatter plots of the dependent variables did not indicate a violation of the linearity assumption required in multivariate analysis.

A post hoc one-way MANOVA was conducted to test the hypothesis that there would be one or more mean differences between the two groups for the five trauma subscales (i.e., PTSD severity, traumatic dissociation, substance abuse, suicidality, PTSD impairment) and the six mental health subscales (i.e., somatization, depression, paranoia, schizophrenia, borderline personality, and social stress). The MANOVA revealed a significant multivariate main effect for group (Wilks' $\lambda=.704, \mathrm{~F}(11,96.00)=3.668, p<.000$ ) with one significant discriminant function. The canonical correlation of .54 indicated that approximately $30 \%$ of the variance was shared between group membership and the discriminant function. As shown in Table 2, the most substantial 
Table 1. Pearson correlations for PTSD and mental health subscales.

\begin{tabular}{|c|c|c|c|c|c|c|c|c|c|c|c|}
\hline Variables & 1 & 2 & 3 & 4 & 5 & 6 & 7 & 8 & 9 & 10 & 11 \\
\hline 1. pts ${ }^{\mathrm{a}}$ & 1.0 & & & & & & & & & & \\
\hline 2. tdis $^{\mathrm{b}}$ & $.43^{* *}$ & 1.0 & & & & & & & & & \\
\hline 3. $\operatorname{sub}^{c}$ & .11 & .02 & 1.0 & & & & & & & & \\
\hline 4. sui ${ }^{\mathrm{d}}$ & $.31^{* *}$ & $.28^{* *}$ & .13 & 1.0 & & & & & & & \\
\hline 5. imp ${ }^{e}$ & $.43^{* *}$ & $.58^{* *}$ & .04 & $.27^{* *}$ & 1.0 & & & & & & \\
\hline 6. $\operatorname{som}^{f}$ & $.37^{* *}$ & $.39^{* *}$ & $.23^{*}$ & $.26^{* *}$ & $.34^{* *}$ & 1.0 & & & & & \\
\hline 7. $d^{g} p^{g}$ & $.40^{* *}$ & $.42^{* *}$ & .17 & $.46^{* *}$ & $.48^{* *}$ & $.61^{* *}$ & 1.0 & & & & \\
\hline 8. $\mathrm{par}^{\mathrm{h}}$ & $.26^{* *}$ & $.42^{* *}$ & .11 & $.36^{* *}$ & $.35^{* *}$ & $.48^{* *}$ & $.53^{* *}$ & 1.0 & & & \\
\hline 9. scz ${ }^{\mathrm{i}}$ & $.35^{* *}$ & $.55^{* *}$ & .18 & $.33^{* *}$ & $.52^{* *}$ & $.64^{* *}$ & $.70^{* *}$ & $.60^{* *}$ & 1.0 & & \\
\hline 10. bor ${ }^{\mathrm{j}}$ & $.33^{* *}$ & $.44^{* *}$ & $.27^{* *}$ & $.40^{* *}$ & $.43^{* *}$ & $.53^{* *}$ & $.60^{* *}$ & $.62^{* *}$ & $.69^{* *}$ & 1.0 & \\
\hline 11. $\operatorname{str}^{\mathrm{k}}$ & $.31^{* *}$ & $.39^{* *}$ & $.29^{* *}$ & $.35^{* *}$ & $.43^{* *}$ & $.53^{* *}$ & $.50^{* *}$ & $.47^{* *}$ & $.57^{* *}$ & $.64^{* *}$ & 1.0 \\
\hline
\end{tabular}

Note. $\mathrm{N}=108 ;{ }^{*}$ Correlations significant at .05 level; ${ }^{* *}$ Correlations significant at .01 level. $\left({ }^{\mathrm{a}}\right.$ PTSD severity score; ${ }^{\mathrm{b}}$ traumatic dissociation; ${ }^{\mathrm{c}}$ substance

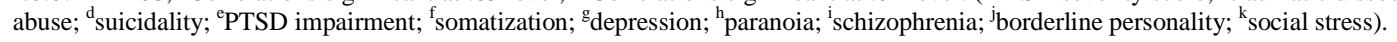

Table 2. Means, confidence intervals, and discriminant weights and loadings for trauma and mental health subscales.

\begin{tabular}{|c|c|c|c|c|c|c|c|c|}
\hline \multicolumn{5}{|c|}{ No Abuse Group $(\mathrm{n}=53)$} & Group ( & & \multirow[b]{2}{*}{$\begin{array}{l}\text { Stan Discrim } \\
\text { Coeff }\end{array}$} & \multirow[b]{2}{*}{$\begin{array}{l}\text { Loadings Discrim } \\
\text { Fn }\end{array}$} \\
\hline Var. & M & $\begin{array}{c}{ }^{*} \mathrm{CI} \\
\text { Lower }\end{array}$ & $\begin{array}{l}{ }^{*} \mathrm{CI} \\
\text { Upper }\end{array}$ & M & $\begin{array}{c}\text { CI } \\
\text { Lower }\end{array}$ & $\begin{array}{c}\text { CI } \\
\text { Upper }\end{array}$ & & \\
\hline${ }^{\mathrm{a}} \mathrm{pts}$ & 104.87 & 98.14 & 111.59 & 103.31 & 96.71 & 109.91 & -.22 & -.01 \\
\hline${ }^{b}$ tdis & 10.04 & 8.86 & 11.21 & 11.31 & 10.18 & 12.46 & .33 & .08 \\
\hline${ }^{\mathrm{c}} \mathrm{sub}$ & 12.38 & 11.06 & 13.67 & 16.16 & 14.90 & 17.43 & .60 & .13 \\
\hline${ }^{\mathrm{d}}$ sui & 15.17 & 13.05 & 17.29 & 18.24 & 16.15 & 20.32 & .25 & .03 \\
\hline eimp & 18.53 & 17.14 & 19.92 & 18.15 & 16.78 & 19.51 & -.44 & -.09 \\
\hline${ }^{\mathrm{f}}$ Som & 31.26 & 27.49 & 35.04 & 38.89 & 35.19 & 42.59 & .28 & .02 \\
\hline${ }^{g}$ dep & 43.72 & 39.94 & 47.49 & 46.47 & 42.77 & 50.18 & -.51 & -.04 \\
\hline${ }^{\mathrm{h}}$ par & 27.57 & 24.51 & 30.62 & 34.00 & 31.00 & 37.00 & .43 & .04 \\
\hline${ }^{\mathrm{i}} \mathrm{SCZ}$ & 28.96 & 25.93 & 31.99 & 33.80 & 30.83 & 36.77 & .16 & .01 \\
\hline${ }^{\mathrm{j}}$ bor & 35.21 & 32.01 & 38.41 & 41.16 & 38.03 & 44.30 & .05 & -.01 \\
\hline${ }^{\mathrm{k}} \mathrm{str}$ & 9.66 & 8.18 & 11.15 & 13.18 & 11.72 & 14.64 & .33 & .06 \\
\hline
\end{tabular}

"95\% Confidence intervals. ( ${ }^{\mathrm{a} P T S D}$ severity score; ${ }^{\mathrm{b}}$ traumatic dissociation; ${ }^{\mathrm{c}}$ substance abuse; ${ }^{\mathrm{d}}$ suicidality; ${ }^{\mathrm{e}} \mathrm{PTSD}$ impairment; ${ }^{\mathrm{f}}$ somatization; ${ }^{\mathrm{g}} \mathrm{depres-}$ sion; ${ }^{\mathrm{h}}$ paranoia; ${ }^{\mathrm{i}}$ schizophrenia; ${ }^{\mathrm{j}}$ borderline personality; ${ }^{\mathrm{k}}$ social stress).

contributions to high scores on the discriminant function (i.e., correlations of .30 or higher; Tabachnick \& Fidell, 2006) were associated high substance abuse, traumatic dissociation, social stress, and paranoia, and low scores for the depression and PTSD impairment subscales. The contribution of somatization and suicidality scores, while noteworthy, did not meet the criterion for inclusion.

Composite variable scores were computed for each participant based on the discriminant loading matrix from the MANOVA. Figure 1 shows mean composite variable scores for four sub-groups, derived from responses to the physical abuse and sexual abuse items from the DAPS life events subscale (physical and sexual abuse [PA + $\mathrm{SA}$ ]: physical abuse only [PA]; sexual abuse only [SA]; and, no abuse [NA]). These data were submitted to nonparametric post hoc analysis given the concerns with small and unequal groups and because the composite vari- 


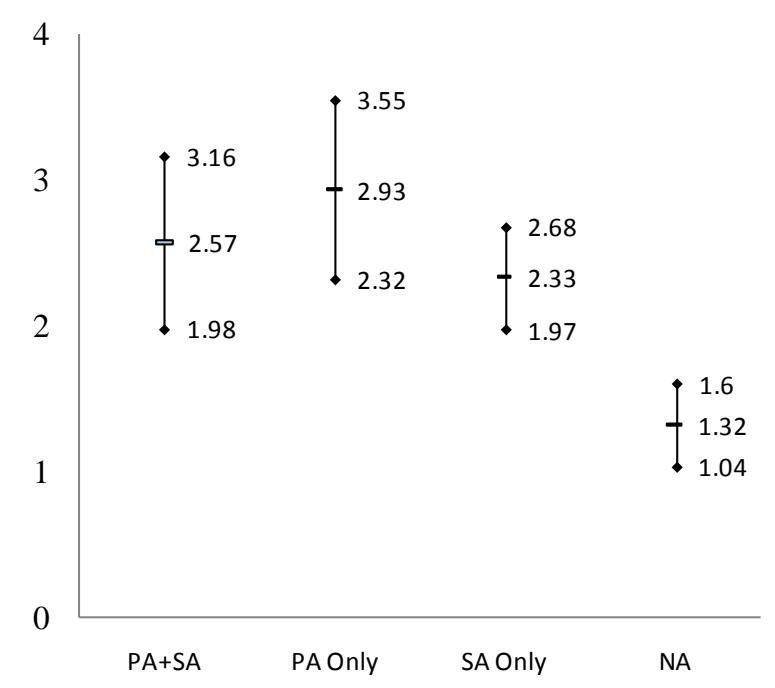

Figure 1. Results of post hoc analysis of abuse sub-groups and non-abuse group for the MANOVA composite variable. Graphic shows mean scores and 95\% confidence intervals for each of the four groups: physical and sexual abuse [PA + $\mathrm{SA}$ ], physical abuse [PA Only], sexual abuse [SA Only], and no abuse [NA].

able from the MANOVA was based on a multivariate distribution. Not surprisingly, the Friedman test, the nonparametric equivalent to the ANOVA, revealed a significant difference between the four groups on the composite variable $\chi^{2}(3)=31.87, p=.000$. A series of three pairwise comparisons through the Wilcoxon signed rank test (nonparametric equivalent to the t-test) evaluated score differences for each of the three abuse groups and the non-abuse group with Bonferroni adjustment $(.05 / 3=.017)$. As shown in Figure 1, significant differences were found between the non-abuse group and the PA + SA group $(\mathrm{Z}=-3.477, p=.001)$, between the non-abuse group and the PA only group ( $\mathrm{Z}=-4.280, p=.000)$, and between the non-abuse group and the SA only group $(\mathrm{Z}=-3.918, p=.000)$.

\section{Discussion}

This study was conducted with the goal of understanding possible effects of developmental abuse among traumatized military veterans. As discussed, a post hoc analysis of assessment data through MANOVA resulted in a composite variable, derived from the linear combination of the mental health and trauma symptom measures, which provided one explanation of the differences between veteran groups with and without abuse histories. This multivariate factor, described as "symptom suppression efforts", indicated that those veterans with childhood physical and sexual abuse who report high rates of substance abuse (i.e., alcohol and cannabis), paranoia, and dissociation, also report lower scores for depression and PTSD impairment scores. This symptom suppression interpretation of the differences between the abuse and non-abuse veteran groups is generally consistent with research linking internal suppression efforts and poor emotional regulation capabilities among military PTSD clients (Klemanski, Mennin, Borelli, Morrissey, \& Aikins, 2012). In the present study, however, these efforts to suppress reactions to trauma appear to be linked with a history of developmental abuse. While beyond the scope of the present study, an intriguing question is whether these efforts to ward-off traumatic reactions were established prior to exposure to military trauma or whether the additive effects of developmental abuse and adult trauma resulted in the pattern of behaviours noted here. One indication of early life efforts to suppress reactions to abuse was that during the clinical interviews many veterans from the abused group reported drinking and using drugs during their adolescence and that their drinking escalated considerably following exposure to military trauma.

Substance abuse and psychogenic dissociation (e.g., depersonalization, derealization) have been reported to be inversely related (see Somer, 2003). In contrast to this finding, a direct relationship was found between substance abuse and dissociative behaviours which may indicate an alternating pattern of substance use and psy- 
chogenic dissociation on a day-to-day basis in the interests of emotional self-regulation. This interpretation is consistent with findings that substance abuse and dissociative behaviours mediate the relationship between childhood abuse and adult PTSD severity (Evren et al., 2011; Schafer et al., 2010). This suggests that selfmanagement behaviours may be established as a consequence of developmental abuse and become obvious during subsequent assessment and treatment of military trauma.

In terms of veterans' interpersonal functioning, these symptom suppression efforts (e.g., substance abuse, paranoia, dissociation) may paradoxically contribute to difficulties with emotional and social engagement (Evren, Sar, Dalbudak, Oncu, \& Cakmak, 2009; Zucker, Spinazzola, Blaustein, \& van der Kolk, 2006), which, in turn, creates challenges for veterans in fostering or accepting social support and likely impairs their ability to engage in therapeutic interventions (e.g., exposure therapy) that require trust and a strong therapy alliance. It is entirely possible that these veterans may resist therapeutic efforts aimed at disrupting over-learned self-containment strategies and, furthermore, that they likely interpret treatment requirements (e.g., abstinence, tolerating emotional flooding) as intensely threatening to their sense of self-control.

Contrary to the hypothesis and prior research showing an additive effect of developmental abuse and military trauma on PTSD symptom severity (e.g., Owens et al., 2009), no differences were found between the abuse and non-abuse veteran groups. One possibility is the presence of a treatment confound in that many of these veterans had been engaged in PTSD treatment prior to their release from the military. Therefore, instead of representing baseline data, these assessments could be capturing positive effects from prior treatment. Even so, the finding is consistent with research noting equivalent PTSD severity for veterans with and without non-military trauma (e.g., Forbes et al., 2013; Keller, Zoeller, \& Feeny, 2010). Importantly, however, Forbes et al. found that combat veterans with non-military trauma did not benefit to the same degree as "combat only" veterans in standard, military focussed interventions. They recommended that veterans with non-military trauma participate in alternative treatment interventions. Indeed, a study of the relationships between adult PTSD, alexithymia and childhood abuse suggested an emotional skill deficit stemming from early development (Frewen, Pain, Dozois, \& Lanius, 2006). These clients may not be equipped to participate in treatments where the ability to identify and to process distressing emotional reactions is often taken for granted.

There is evidence that traumatized military personnel with complex developmental histories may benefit from group psychotherapy programs (Barrera, Mott, Hofstein, \& Teng, 2013; Ready, Vega, Worley, \& Bradley, 2012; Whelan, 2013b) where titrated emotional exposure and mutuality may facilitate social re-integration (Lieberman, 2013). As noted by Rademaker et al. (2009), trauma groups “...can help to recreate some of the (narcissistic) identifications that were present during military training and the mission thereby helping to reconstruct the context in which the trauma occurred” (p. 484). The military ethos of group cohesion and backing up one's battle buddies, mutual identification, and shared experience may help tremendously in establishing psychological safety prior to therapeutic efforts aimed at disrupting symptom suppression behaviours, including paranoia and emotional avoidance. The findings here indicate that group interventions should ideally be conducted within a developmental framework. Potential program formats include a multi-modal residential program for developmental trauma and military PTSD (Busuttil, 2006) or a group-based exposure program for war-related trauma (Ready et al., 2008), both of which showed significant and lasting improvements.

As a follow-up to the present study, a developmentally-focussed, outpatient group program was offered to the abused veterans and showed positive results over a 36-month period for trauma symptoms, general mental health, and quality of life outcomes (Whelan, 2013b). In the end, the findings re-enforce the importance of conducting developmentally focussed assessments of military trauma and highlight the need to develop interventions that attend to events across the developmental spectrum.

\section{Limitations and Future Research}

This study identified symptom profiles among developmentally abused veterans which may offer a partial explanation for post-release treatment relapse. There are important limitations to the findings. Importantly, the results are not generalizable to the broader population of military personnel who develop PTSD. In the absence of a control group of veterans with developmental abuse histories who may have been successful during prior treatment, it was not possible to evaluate the extent or broader implications of symptom suppression efforts. Inclusion of a control group would allow for identification of other factors (e.g., lack of unit support, notification of medical release during treatment) that may have influenced treatment outcomes for developmentally abused 
veterans.

This study focussed on a categorical rating to assess physical and sexual abuse; measures that assess the severity and frequency of these experiences would provide a better understanding of their relationships with trauma and mental health symptom severity. Future studies should also focus on the inter-relationships between physical and sexual abuse, and emotional abuse. In recent studies, the latter has been shown to have a strong relationship with adult-onset alcohol and pathological dissociation (Schafer et al., 2007). It is possible that the emotional antecedents and aftermath of physical and sexual abuse may contribute to the symptom suppression efforts noted in the present study.

\section{References}

Baker, D. G., Nievergelt, C. M., \& Risbrough, V. B. (2009). Posttraumatic Stress Disorder: Emerging Concepts of Pharmacotherapy. Expert Opinion Emergent Drugs, 14, 251-272. http://dx.doi.org/10.1517/14728210902972494

Barrera, T. L., Mott, J. M., Hofstein, R. F., \& Teng, E. J. (2013). A Meta-Analytic Review of Exposure in Group Cognitive Behavioral Therapy for Posttraumatic Stress Disorder. Clinical Psychology Review, 33, 24-32. http://dx.doi.org/10.1016/j.cpr.2012.09.005

Blake, D., Weathers, F., Nagy, L., Kaloupek, D., Klaumenzer, G., Charney,... Buckley, T. C. (2000). Instruction Manual: Clinician-Administered PTSD Scale (CAPS). West Haven: National Center for Posttraumatic Stress Disorder Behavioral Science Division, Boston Neurosciences Division.

Briere, J. (2001). DAPS—Detailed Assessment of Posttraumatic Stress Professional Manual. Odessa, FL: Psychological Assessment Resources.

Brown, P. J., Stout, R. L., \& Mueller, T. (1999). Substance Use Disorder and Posttraumatic Stress Disorder Comorbidity: Addiction and Psychiatric Treatment Rates. Psychology of Addictive Behaviors, 13, 115-122. http://dx.doi.org/10.1037/0893-164X.13.2.115

Busuttil, W. (2006). The Development of a 90-Day Residential Program for the Treatment of Complex Posttraumatic Stress Disorder. Journal of Aggression, Maltreatment, \& Trauma, 12, 29-55. http://dx.doi.org/10.1300/J146v12n01 03

Cabrera, O. A., Hoge, C. W., Bliese, P. D., Castro, C. A., \& Messer, S. C. (2007). Childhood Adversity and Combat as Predictors of Depression and Post-Traumatic Stress in Deployed Troops. American Journal of Preventative Medicine, 33, 77-82. http://dx.doi.org/10.1016/j.amepre.2007.03.019

Evren, C., Sar, V., Dalbudak, E., Oncu, F., \& Cakmak, D. (2009). Social Anxiety and Dissociation among Male Patients with Alcohol Dependency. Psychiatry Research, 165, 273-280. http://dx.doi.org/10.1016/j.psychres.2007.10.016

Evren, C., Sar, V., Dalbudak, E., Cetin, R., Durkaya, M., Evren, B., \& Celik, S. (2011). Lifetime PTSD and Quality of Life among Alcohol-Dependent Men: Impact of Childhood Emotional Abuse and Dissociation. Psychiatry Research, 186, 85-90. http://dx.doi.org/10.1016/j.psychres.2010.07.004

Felitti, V. J., \& Anda, R. F. (2010). The Relationship of Adverse Childhood Experiences to Adult Health, Well-Being, Social Function, and Healthcare, In R. Lanius, E. Vermetten, \& C. Pain (Eds.). The Impact of Early Life Trauma on Health and Disease; The Hidden Epidemic (pp. 77-87). New York: Cambridge University Press.

Forbes, D., Fletcher, S., Phelps, A., Wade, D., Creamer, M., \& O’Donnell, M. (2013). Impact of Combat and Non-Military Trauma Exposure on Symptom Reduction Following Treatment for Veterans with Posttraumatic Stress Disorder. Psychiatry Research, 206, 33-36. http://dx.doi.org/10.1016/j.psychres.2012.09.037

Frewen, P. A., Pain, C., Dozois, D. J., \& Lanius, R. A. (2006). Alexithymia in PTSD: Psychometric and fMRI Studies. Annals of the New York Academy of Science, 1071, 397-400. http://dx.doi.org/10.1196/annals.1364.029

IBM Corp. Released 2011. IBM Statistics for Windows, Version 20.0. Armonk, NY: IBM Corp.

Keller, S. M., Zoeller, L. A., \& Feeny, N. C. (2010). Understanding Factors Associated with Early Therapeutic Alliance in PTSD Treatment: Adherence, Childhood Sexual Abuse History, and Social Support. Journal of Consulting and Clinical Psychology, 78, 974-979. http://dx.doi.org/10.1037/a0020758

Kitchiner, N. J., Roberts, N. P., Wilcox, D., \& Bisson, J. I. (2012). Systematic Review and Meta-Analysis of Psychosocial Interventions for Veterans of Military. European Journal of Psychotraumatology, 3, 1-16. http://dx.doi.org/10.3402/ejpt.v3i0.19267

Klemanski, D. H., Mennin, D. S., Borelli, J. L., Morrissey, P. M., \& Aikins, D. E. (2012). Emotion-Related Regulatory Difficulties Contribute to Negative Psychological Outcomes in Active-Duty Iraq War Soldiers with and without Posttraumatic Stress Disorder. Depression and Anxiety, 29, 621-628. http://dx.doi.org/10.1002/da.21914

Kozaric-Kovacic, D. (2008). Psychopharmacotherapy of Posttraumatic Stress Disorder. Croatian Medical Journal, 49, 459475. http://dx.doi.org/10.3325/cmj.2008.4.459 
Lieberman, M. D. (2013). Social: Why Our Brains Are Wired to Connect. New York: Crown Publishers.

Mikulak, A. (2012). Embattled Childhoods May Be the Real Trauma for Soldiers with PTSD. http://www.sciencedaily.com/releases/2012/11/121119140625.htm.

Morey, L. C. (1991). Personality Assessment Inventory Professional Manual. Lutz, FL: Psychological Assessment Resources.

Morey, L. C. (2008). PAI Software Portfolio, Version 3. Lutz, FL: Psychological Assessment Resources.

Nilamadhab, K. (2011). Cognitive behavioral Therapy for the Treatment of Post-Traumatic Stress Disorder: A Review. Neuropsychiatric Disease and Treatment, 7, 167-181.

Norman, S. B., Tate, S. R., Anderson, K. G., \& Brown, S. A. (2007). Do Trauma History and PTSD Symptoms Influence Addiction Relapse Context? Drug and Alcohol Dependence, 90, 89-96.

http://dx.doi.org/10.1016/j.drugalcdep.2007.03.002

Owens, G. P., Dashevsky, B., Chard, K. M., Mohamed, S., Haji, U., Heppner, P. S., \& Baker, D. G. (2009). The Relationship between Childhood Trauma, Combat Exposure, and Posttraumatic Stress Disorder in Male Veterans. Military Psychology, 21, 114-125. http://dx.doi.org/10.1080/08995600802574530

Pagano, R. G. (1997). Understanding Statistics in the Behavioral Sciences (3rd ed.). New York: West Publishing Co.

Rademaker, A. R., Vermetten, E., \& Kleber, R. J. (2009). Multimodal Exposure-Based Group Treatment for Peacekeepers with PTSD: A Preliminary Evaluation. Military Psychology, 21, 482-496. http://dx.doi.org/10.1080/08995600903206420

Ravindran, L. N., \& Stein, M. B. (2009). Pharmacotherapy of PTSD: Premises, Principles, and Priorities. Brain Research, 13, 24-39. http://dx.doi.org/10.1016/j.brainres.2009.03.037

Ready, D. J., Thomas, K. R., Worley, V., Backschieder, A. G., Harvey, L. C., Baltzell, D., \& Rothbaum, B. O. (2008). A Field Test of Group-Based Exposure Therapy with War-Related Posttraumatic Stress Disorder. Journal of Traumatic Stress, 21, 150-157. http://dx.doi.org/10.1002/jts.20326

Ready, D. J., Vega, E. M., Worley, V., \& Bradley, B. (2012). Combining Group-Based Exposure Therapy with Prolonged Exposure to Treat U.S. Vietnam Veterans with PTSD: A Case Study. Journal of Traumatic Stress, 25, 574-577. http://dx.doi.org/10.1002/jts.21734

Schafer, I., Langeland, W., Hissbach, J., Luedecke, M., Ohlmeier, M., Chodzinski, C. et al., TRAUMAB-Study Group (2010). Childhood Trauma and Dissociation in Patients with Alcohol Dependence, Drug Dependence, or Both—A MultiCenter Study. Drug and Alcohol Dependence, 109, 84-89. http://dx.doi.org/10.1016/j.drugalcdep.2009.12.012

Schafer, I., Reininghausa, U., Langeland, W., Vossa, A., Ziegera, N., Haasena, C., \& Karowa, A. (2007). Dissociative Symptoms in Alcohol-Dependent Patients: Associations with Childhood Trauma and Substance Abuse Characteristics. Comprehensive Psychiatry, 48, 539-545. http://dx.doi.org/10.1016/j.comppsych.2007.05.013

Schottenbauer, M. A., Glass, C. R., Arnkoff, D. B., \& Gray, S. H. (2008). Contributions of Psychodynamic Approaches to Treatment of PTSD and Trauma: A Review of the Empirical Treatment and Psychopathology Literature. Psychiatry, 71, 13-34. http://dx.doi.org/10.1521/psyc.2008.71.1.13

Schumacher, J. A., Coffey, S. F., \&Stasiewicz, P. R. (2006). Symptom Severity: Alcohol Craving, and Age of Trauma Onset in Childhood and Adolescent Trauma Survivors with Comorbid Alcohol Dependence and Posttraumatic Stress Disorder. American Journal on Addictions, 15, 422-425. http://dx.doi.org/10.1080/10550490600996355

Seifert, A. E., Polusny, M. A., \& Murdoch, M. (2011). The Association between Childhood Physical and Sexual Abuse and Functioning and Psychiatric Symptoms in a Sample of U.S. Army Soldiers. Military Medicine, 176, 176-181. http://dx.doi.org/10.7205/MILMED-D-10-00038

Sharpless, B. A., \& Barber, J. P. (2011). A Clinician’s Guide to PTSD Treatments for Returning Veterans. Professional Psychology Research and Practice, 42, 8-15. http://dx.doi.org/10.1037/a0022351

Solomon, Z., Zur-Noah, S., Horesh, D., Zerach, G., \& Keinan, G. (2008). The Contribution of Stressful Life Events throughout the Life Cycle to Combat-Induced Psychopathology. Journal of Traumatic Stress, 21, 318-325. http://dx.doi.org/10.1002/jts.20340

Somer, E. (2003). Prediction of Abstinence from Heroin Addiction by Childhood Trauma, Dissociation, and Extent of Psychosocial Treatment. Addiction Research and Theory, 11, 339-348. http://dx.doi.org/10.1080/1606635031000141102

Tabachnick, B. G., \& Fidell, L. S. (2006). Using Multivariate Statistics (5th ed). Boston, MA: Allyn and Bacon.

Thompson, J., MacLean, M. B., Van Til, L., Sweet, J., Poirier, A., \& Pedlar, D. (2011). Survey on Transition to Civilian Life: Report on Regular Force Veterans. Research Directorate, Veterans Affairs Canada, and Director General Military Personnel Research and Analysis, Department of National Defence, Ottawa.

Van Voorhees, E. E., Dedert, E. A., Calhoun, P. S., Brancu, M., Runnals, J., VA Mid-Atlantic MIRECC Workgroup, \& Beckham, J. C. (2012). Childhood Trauma Exposure in Iraq and Afghanistan War Era Veterans: Implications for Post- 
traumatic Stress Disorder Symptoms and Adult Functional Social Support. Child Abuse \& Neglect, 36, 423-432. http://dx.doi.org/10.1016/j.chiabu.2012.03.004

Wampold, B. E., Imel, Z. E., Laska, K. M., Benish, S., Miller, S. D., Fluckiger, C. et al. (2010). Determining What Works in the Treatment of PTSD. Clinical Psychology Review, 30, 923-933. http://dx.doi.org/10.1016/j.cpr.2010.06.005

Whelan, J. J. (2013a). Exploring the Relationships between Untreated Adverse Childhood Events and Substance Abuse, and Their Impact on PTSD Relapse Rates among Canadian Military Veterans. In A. B. Aiken, \& A. H. Belanger (Eds.), Beyond the Line: Military and Veteran Health Research (pp. 180-195). Kingston, ON: McGill-Queen’s University Press.

Whelan, J. J. (2013b). Description and Treatment Outcomes for the Trauma Relapse Prevention Group (TRPG) Program. Poster presented at the annual conference of the Canadian Institute on Military and Veteran Health Research, Edmonton, AB.

Zucker, M., Spinazzola, J., Blaustein, M., \& van der Kolk, B. A. (2006). Dissociative Symptomatology in Posttraumatic Stress Disorder and Disorders of Extreme Stress. Journal of Trauma \& Dissociation, 7, 19-31.

http://dx.doi.org/10.1300/J229v07n01 03 